\title{
Astım ve COVID-19
}

\section{Asthma and COVID-19}

\author{
Esra Yücel ${ }^{1}\left(\mathbb{D}\right.$, Zeynep Tamay $^{1}$ (1) \\ ${ }^{1}$ isstanbul Üniversitesi, İstanbul Tıp Fakültesi, Çocuk Sağlığı ve Hastalıkları, Çocuk İmmunoloji ve Allerji Bilim Dalı, İstanbul, Türkiye
}

ORCID ID: E.Y. 0000-0003-3712-2522; Z.T. 0000-0002-3200-5493

Attf/Citation: Yucel E, Tamay Z. Astım ve COVID-19. Çocuk Dergisi - Journal of Child 2020;20(2):76-79. https://doi.org/10.26650/jchild.2020.2.738379

öz

Son günlerde ülkemiz ve tüm dünyayı etkisi altına alan COVID-19 pandemisi önemli bir halk sağlığı sorunu olmuştur. Salgında astımlı hastaların da etkilenmesi mümkündür. Bu aşamada hekimlerin astımlı hastalara doğru yaklaşımı astım COVID-19 arasındaki ilişkinin ortaya konması ile sağlanabilir. Şu ana kadar kontol altındaki astımlılar için COVID-19'un için ek risk getirmediği oluşturmadığı bildirilmişti. Ancak yine de astım hastalarının sosyal izolasyon ve kişisel hijyen kurallarına uymalarının sağlanması önemlidir. Yeni bilgiler elde edilinceye kadar astımın mevcut rehberlere göre tedavi edilmesi uygun bir yaklaşımdır.

Anahtar Kelimeler: Astım, COVID-19, SARS-CoV-2

\section{ABSTRACT}

Pandemic of COVID-19 which has recently influenced our country and the global world, has been an important public health problem. It is possible that patients with asthma may also be affected in this outbreak. At this stage, the correct approach of physicians to patients with asthma can be achieved by revealing the relationship between asthma and COVID-19. Up to now, it has been reported that COVID-19 controlled asthma does not pose an additional risk for controlled asthma COVID-19. However, it is still important to ensure that patients with asthma follow social isolation and personal hygiene rules. Treating asthma according to current guidelines is an appropriate approach, until new information is available.

Keywords: Asthma, COVID-19, SARS-CoV-2

\section{COVID-19; Genel Bilgiler ve Epidemiyoloji}

Koronavirüsler, Coronaviridae ailesi, Orthocoronavirinae alt ailesi içinde yer alırlar. Orthocoronovirinaea alt ailesi içinde de çok sayıda alt cins bulunmaktadır. Bu cinsler altındaki virüsler insan, yarasa, domuz, kedi, köpek, kemirgen ve kanatlılar gibi evcil ve yabani hayvanlarda bulunabilmektedir. Insanlarda koronavirüsler basit soğuk algınlığından ağır akut solunum sendromuna kadar değişkenlik gösteren bir çeşitlilikte hastalığa neden olmaktadır (1).

Aralık 2019 sonunda Çin'in Hubei Eyaleti, Wuhan şehrinden bildirilen etkeni belli olmayan pnömoni vakalarında ilk kez 7 Ocak 2020'de daha önce insanlarda tespit edilmemiş yeni bir koronavirüs tanımlanmıştır. Bu virüs, ciddi akut solunum yolu sendromu koronavirüsü (Severe Acute Respiratory Syndrome Coronavirus, SARS-CoV) ve Ortadoğu respiratuvar sendrom koronavirüsü (Middle East Respiratory Syndrome Coronavirus, MERS-CoV)'nün de içinde bulunduğu beta koronavirüs ailesinden olup SARS-CoV-2 olarak adlandırılmıştır. Oluşturduğu hastalığın adı da COVID-19 olarak kabul edilmiştir (1). Bildirildiği tarihten bu yana hasta sayısı gerek Çin'de gerekse tüm dünyada hızla artmış olup insandan insana bulaşma özelliği nedeniyle hızla yayılmıştır. Ülkemizde ilk vaka 11 Mart 2020'de saptanmıştır. Eş zamanlı olarak Dünya Sağlık Örgütü (DSÖ) COVID-19'u pandemik hastalık olarak ilan etmiştir (2). T.C. Sağlık Bakanlığı ülkemizin tüm illerinde hastalığın görüldüğü açıklamıştır ve güncel toplam vaka sayısı 141,475 ve iyileşen hasta sayısı 98,889'dur (3).

Hastalığın kaynağı henüz netleştirilmemiştir. Salgının ilk başlangıç noktasının Wuhan'da yer alan bir deniz ürünleri hali olduğu, burada yasadışı olarak satlan vahşi hayvanlardan kaynaklanabileceği düşünülmüştür. İnsandan insana bulaş esas olarak hasta bireylerden damlacık yolu ile olmaktadır. Virüs yüzeylerdeki damlacıklara ellerle temas ve sonrasında ağız, göz, buruna dokunulması ile mukozalardan vücuda girmektedir. COVID-19'un bulaştırıcılık süresi ve dış ortama dayanma süresi

Sorumlu Yazar/Corresponding Author: Esra Yücel E-mail: esraozek@yahoo.com

Başvuru/Submitted: 27.07.2020 • Revizyon Talebi/Revision Requested: 31.08.2020 • Son Revizyon/Last Revision Received: 05.09.2020 • Kabul/Accepted: 07.09.2020 
net olarak bilinmemekte, ortalama inkübasyon süresinin 2-14 gün olduğu, bulaştırıcılığın da semptomatik dönemden 1-2 gün önce başlayıp semptomların kaybolmasıyla sona erdiği düşünülmektedir ancak semptomlar bittikten sonra da bulaştırıcı olabilmektedir (1).

\section{Klinik Bulgular}

COVID-19'un sık görülen yaygın belirtileri solunum semptomları, ateş, öksürük ve dispnedir. Daha az sıklıkta da baş ağrısı, kas ağrısı, tat ve koku kaybı görülebilmektedir. Daha ciddi vakalarda, pnömoni, ağır akut solunum yolu enfeksiyonu ve çoklu organ yetmezliği, hemofagositik lenfohistiositoz ve septik şoka ilerleyen ölümcül bir klinik tablo görülebilir $(1,4)$.

Fatalite hızı SARS salgınında \%11 ve MERS-CoV'da \%35-50 arasında bildirilmiştir (1). Çin'den elde edilen verilere göre COVID-19 hastalığının fatalite hızı \%3,8 olarak bildirilmiştir ve yüksek riskli hastalarda (hipertansiyon, ileri yaş, obezite) bu oran artabilmektedir $(1,5)$. Diğer ülkelerde hastalık seyrinin değişken olabilmesi, asemptomatik ve hafif semptomatik hastaların analizlere dahil edilip edilmeme durumu fatalite hızının ülkelere göre farklılıklar göstermesine yol açabilir.

\section{Astım ve COVID-19 ilişkisi}

Astım dünya çapında önemli bir sağlık sorunudur. SARS-CoV-2 solunum yolu patojeni olduğundan, şu anda COVID-19 salgını sürerken astım hastalarının nasıl bir risk altında olduğunu bilmek önemlidir. Özellikle ağır seyir ile ilişkili faktörlerin belirlenmesi koruyucu önlemlerin alınması, erken tanı ve tedavinin yönlendirilmesi için önem kazanmaktadır. Hasta serilerinden elde edilen bilgiler mortalite ve morbiditenin altta yatan hipertansiyon, kardiyovasküler hastalığı olanlar ve obezlerde daha fazla olduğu şeklindedir. Astım nedeniyle COVID-19 için spesifik bir risk artışı ya da SARS-CoV-2 ile enfekte astım hastalarında daha ağır seyir ile ilişki gösterilmemiştir. Yine sigara içiciliği de ağır COVID-19 için risk faktörü olarak bildirilmiştir ancak pasif sigara maruziyetinin değerlendirildiği bir veri mevcut değildir (6-8). İleri yaş da yine mortalite ve ağır COVID-19 için risk faktörüdür (6-8). Ancak elde edilen bu ilk veriler salgının başladığı Çin ve Uzak Doğu ülkelerine aittir. Amerika Birleşik Devletleri verilerine göre yine hipertansiyon, kalp hastalıkları ve obezite COVID-19 nedeniyle yatan hastalarda en sık görülen komorbiditelerdir (9). Astım yatan hastaların \%9'una eşlik etmektedir. Çocukluk çağında COVID-19 seyri erişkin hastalara göre daha hafif gidişlidir. Daha çok asemptomatik ya da hafif-orta ağırıkta hastalık görülmektedir. Ağır hastalık tüm çocuk vakaların \% 0,6'sından azında görülmüştür (9-11).

Astımın ağır COVID-19 hastalığı için güçlü bir risk faktörü olmadığı 140 COVID-19 hastasının alındığı bir çalışmada gösterilmiştir (12). Yine farklı kliniğe sahip hastaların derlendiği yazılarda astım eşlik eden bir hastalık olarak bildirilmemiştir $(13,14)$. Bu bilgiler astım hastalarında COVID-19'un ağır seyri riskinin önemli ölçüde artmayacağını düşündürmektedir ancak bu verilerin sadece yatan hastaları kapsaması nedeniyle hafif semptomları olan COVID-19'lu hastalarda astım açısından durumun değerlendirmediği akılda tutulmalıdır. Buna rağmen Amerika Birleşik
Devletleri verilerine göre $18-49$ yaş arası COVID -19 nedeniyle yatan hastaların \%23'ünde, 50-64 yaş arasında \%13,2'sinde, 65 yaş üzerinde ise \%12,9 oranında astım eşlik etmektedir. Bu nedenle Amerikan Astım Alerji ve İmmünoloji Akademisi (AAAAI) özellikle 18-49 yaş bireylerde astımın, COVID-19 nedeniyle yatış için risk faktörü olabileceğini işaret etmiştir $(15,16)$. Ek olarak daha çok ağır astım ya da kontrolsüz astımın COVID-19 için risk oluşturduğu düşünülmektedir (17).

\section{COVıD-19 Salgını Sırasında Astım Açısından Öneriler}

Enfeksiyonun yol açtığı pnömoni ve buna bağlı solunum sıkıntısı riski dışında SARS-CoV-2'nin de astım atağını tetikleme riski teorik olarak mevcuttur. Bu asıl olarak pandemik olmayan koronavirüsler için geçerlidir (18). Bu nedenle astım hastalarının daha ağır bir atak olasılığını azaltmak için astım hastalığının mutlaka kontrol altında olması gereklidir. Bunu sağlayabilmek için böyle bir salgın döneminde hastaların kontrol edici inhale steroid içeren ilaçlarını kesmemeleri gerekmektedir. Kontrol edici tedavinin kesilmesi diğer nedenlere bağlı atak geçirme olasılığını bu da sağlık merkezine başvuru sırasında SARS-CoV2'ye maruz kalma riskini arttracaktır (18). Yine hastaların astım için bir süredir sistemik steroid kullanımları olmuşsa bu tedaviyi de hekimlerine danışmadan kesmemeleri gerekmektedir.

Astımlı hastaların da herkes gibi pandemi dönemini evlerinde geçirmeleri, sosyal izolasyona dikkat etmeleri ve hasta bireylerden en az 2 metre uzak durmaları önemlidir. Genel önlemler olarak ellerin en az 20 saniye su ve sabun ile yıkanması veya \%70 alkol içeren bir el dezenfektanı kullanılması astım hastalarına da tavsiye edilmektedir. Öksürük ve hapşırık sırasında peçete kullanımı, gözler, burun ve ağıza dokunulmaması, sık dokunulan yüzeylerin (masa, kapı kolu, cep telefonu vb...) temizlenmesi virüs bulaşını azaltmaya yönelik alınması gereken diğer önlemlerdir.

İnhale steroidlerin aksine sistemik kortikosteroidlerin viral replikasyonu arttırma potansiyeli nedeniyle COVID-19 tanısı olan hastalarda rutin olarak kullanılmaması önerilmektedir. Russell ve ark. koronavirüslerden kaynaklanan akciğer hasarını azaltmak için kullanılan sistemik steroidlerin etkinliğinin muhtemelen az olacağını bildirmiştir (19). Sistemik kortikosteroid tedavisinin sadece mekanik ventilasyondaki akut respiratuvar distres sendromu (ARDS) olgularında metilprednizolon 1-2 mg/ $/ \mathrm{gg} /$ gün dozda 5-7 gün olarak zayıf kanıt düzeyi ile önerilmektedir. ARDS olmayan pnömonide ise önerilmemektedir (20). Akut astım atağı yine rehberlerin önerdiği şekilde tedavi edilmelidir, bu sırada oral kortikosteroid kullanımından kaçınmamak gerekmektedir $(20,21)$.

COVID-19 sırasında solunum fizyoterapisine yönelik uygulamalar hastalığın akut döneminde önerilmemektedir (22).

Viral üst solunum yolu enfeksiyonu, akut bronşiyolit ve akut astım atağı ile COVID-19 semptomları örtüşme gösterebilmektedir. Ateş, öksürük, nefes darlığı yakınmaları bu hastalıklar için benzer şikayetlerdir. Yine çocuk hasta grubunda hışılt da olabileceği bildirilmiştir. Bu nedenle hekimler tanısal ayırımda güçlükler yaşayabilirler. Burada temas öyküsü olup olmadığı mutlaka sorgulanmalıdır. Yine ani başlangıçlı ateş ile birlikte 
öksürük veya nefes darlığı olması ve burun akıntısının olmaması, tat ve koku duyusunda kusur olması daha çok COVID-19 lehine değerlendirmelidir (1).

COVID-19 salgını sırasında astımlı hastaların tedavisinde nebulizatör kullanımı gerekli olmadıkça önerilmemektedir çünkü nebulize tedavi sırasında virüsün aerosolize olarak bulaş riskini arttıracağı düşünülmektedir. Bu nedenle hem hastanede hem de evde nebülize tedavi yerine aracı tüp ile ölçülü doz inhaler veya kuru toz inhaler kullanmak en uygun yaklaşım olacaktır. Ideal olan her hastaya ayrı aracı tüp kullanımının sağlanmasıdır (23-27).

Nebülizatör kullanımı daha çok ölçülü doz inhaler ya da kuru doz inhalere yanıt vermeyen hastalara, bu cihazlar ile inhale tedavilere uyum sağlayamayan hastalara ya da hipoventilasyon, kistik fibrozis veya devamlı nebülizasyon gerektiren özellikli hastalara yapılmalıdır (24).

Nebülizasyon işlemi aerosolize halde virüs dağılımını arttıran uygulamalardan biri olduğu için tedaviyi düzenleyen sağlık çalışanının N95 maske üzerine tek kullanımlık cerrahi maske takması ve sonrasında cerrahi maskesini çıkarması önerilmektedir. Nebülize ilaç verilmesi mutlak gerekli ise hastanın etrafinda en az $2 \mathrm{~m}$ boşluk olmalıdır. Münkünse nebülizatör ile ilaç uygulaması için mesh nebülizatör kullanımı tercih edilmelidir (24). COVID-19 tanılı hastada nebülizatör ile ilaç uygulaması yapılacak ise tercihen negatif basınçlı odada yapılmalı, hastada dışarıya açık maske yerine ek olarak bakteri filtresi takılmış invazif olmayan ventilasyon maskesi kullanılması daha uygun bir yaklaşım olacaktır (27).

Bazı ağır astımlı hastaların tedavisinde anti-interlökin (IL) 5 veya anti-immunglobulin (Ig) E gibi biyolojik ajanların kullanılması gerekebilmektedir. Hastaların fayda görmeleri halinde COVID-19 salgını sırasında da biyolojik ajan tedavisine devam edilmesi uygun olacaktir $(17,18,28)$.

Astıma eşlik eden alerjik rinit, atopik dermatit gibi hastalıklarda da kontrol edici tedavilere aynen devam edilmesi gerekmekte$\operatorname{dir}(18,28)$. Besin alerjisi eşlik eden hastalarda da mümkünse bu dönemde besin denemesinden kaçınılması uygun olacaktır (18).

COVID-19 hastalarının bir kısmını da enfekte sağlık personeli oluşturmaktadır, Çin'de 3300 sağlık çalışanı enfekte olmuş, İtalya'da bu oran \%20 civarında olup bir kısmı ağır hastalık geçirip hayatını kaybetmiştir (29). Bu ciddiyette bir salgınla mücadele ederken özellikle sağlık sisteminin elinde olan sağlık çalışanını, malzeme, yatak kapasitesi gibi kaynaklarını etkili ve yerinde kullanılması önem kazanmaktadır. Bu nedenle hem hastayı hem de hekimi korumak adına acil durumlar dışında planlı sağıı hizmetlerinde ertelemeler yapılabilir, bu alerjik hastalıklar için de geçerlidir (18). Kontrollü astımı olan hastaların (son 6 ay-1 yıl içinde akut astım atağı geçirmeyen bu nedenle acil başvurusu olmayan ve sistemik steroid kullanması gerekmeyen hastalar) rutin muayene randevuları ertelenebilir. Salgın döneminde solunum fonksiyon testlerinin yapılması önerilmemektedir $(17,18,28)$.
Pandemi döneminde alerjen spesifik immünoterapi tedavisine başlanmamalıdır. Venom immünoterapisi gibi yüksek riskli hastaların ise immünoterapisine devam edilmelidir. Alerjen spesifik immünoterapi alan hastalar doz arttrma ve idame fazında gelinen aşamaya göre doz şemasında erteleme yapılması mümkündür $(30,31)$. Yine sublingual immünoretapi alan hastalar evde tedavilerine devam edebilirler. Ancak aktif olarak COVID-19 geçiren hastaların subkutan ya da sublingual immünoterapi tedavilerine ara verilip, hasta tamamen iyileştikten ve yeterli SARS-CoV-2 antikor yanıt oluştuktan sonra tekrar başlanmalıdır (31).

\section{SONUÇ}

Sonuç olarak astım ile COVID-19 arasındaki ilişkinin anlaşılması hastaların doğru tedavi ve takibi için önemlidir. Astımdan dolayı COVID-19 açısından artan bir risk ya da koruyucu olduğunu gösteren veriler şu anda yetersiz olsa da yine de astım hastalarının sosyal izolasyon ve kişisel hijyen kurallarına uymalarının sağlanması önemlidir. Yakın gelecekte elde edeceğimiz yeni bilgiler aksini kanıtlayana kadar hekimlerin astımı mevcut rehberlerin astım yönergelerine göre tedavi etmeye devam etmeleri uygun olacaktır.

Hakem Değerlendirmesi: Dış bağımsız.

Yazar Katkıları: Çalışma Konsepti/Tasarım- E.Y., Z.T.; Yazı Taslağı- E.Y.; İçeriğin Eleştirel İncelemesi- Z.T.; Son Onay ve Sorumluluk- E.Y., Z.T

Çıkar Çatışması: Yazarlar çıkar çatışması beyan etmemişlerdir.

Finansal Destek: Yazarlar finansal destek beyan etmemişlerdir.

Peer Review: Externally peer-reviewed.

Author Contributions: Conception/Design of Study- E.Y., Z.T.; Drafting Manuscript- E.Y.; Critical Revision of Manuscript- Z.T.; Final Approval and Accountability- E.Y., Z.T.

Conflict of Interest: Authors declared no conflict of interest.

Financial Disclosure: Authors declared no financial support.

\section{KAYNAKLAR/REFERENCES}

1. T.C. Sağlık Bakanlığı Halk Sağlığı Genel Müdürlüğü COVID-19 (SARSCoV-2 Enfeksiyonu) Rehberi. Erişim: https://covid19bilgi.saglik.gov. tr/depo/rehberler/COVID19. Son erişim tarihi: 14.04.2020.

2. WHO Director-General's opening remarks at the media briefing on COVID-19 - 11 March 2020. https://www.who.int/dg/speeches/ detail/who-director-general-s-opening-remarks-at-the-mediabriefing-on-covid-19---11-march-2020

3. COVID-19 Durum Raporu. https://covid19.saglik.gov.tr/TR-68443/ covid-19-durum-raporu.html. 5.4.2020

4. Lupia T, Scabini S, Pinna SM, Di Perri G, De Rosa FC, Corcione S. 2019-novel Coronavirus Outbreak: A New Challenge. J Glob Antimicrob Resist 2020 Jun;21:22-27. doi: 10.1016/j. jgar.2020.02.021. Epub 2020 Mar 7. PMID: 32156648; PMCID: PMC7102618. 
5. Onder G, Rezza G, Brusaffero S. Case-Fatality Rate and Characteristics of Patients Dying in Relation to COVID-19 in Italy. JAMA 2020 May 12;323(18):1775-1776. doi: 10.1001/jama.2020.4683. Erratum in: JAMA. 2020 Apr 28;323(16):1619. PMID: 32203977.

6. Yang J, Zheng Y, Gou X, Pu K, Chen Z, Guo Q, et al. Prevalence of comorbidities in the novel Wuhan coronavirus (COVID-19) infection: a systematic review and meta-analysis, Int J Infect Dis 2020 May;94:91-95. doi: 10.1016/j.ijid.2020.03.017. Epub 2020 Mar 12. PMID: 32173574; PMCID: PMC7194638.

7. Jordan RE, Adab P, Cheng KK. Covid-19: risk factors for severe disease and death. BMJ 2020 Mar 26;368:m1198. doi: 10.1136/ bmj.m1198. PMID: 32217618.

8. Shi Y, Yu X, Zhao H, Wang H, Zhao R, Sheng J. Host susceptibility to severe COVID-19 and establishment of a host risk score: findings of 487 cases outside Wuhan. Crit Care. 2020 Mar 18;24(1):108. doi: 10.1186/s13054-020-2833-7. PMID: 32188484; PMCID: PMC7081524.

9. Richardson S, Hirsh JS, Narasimhan M, Crawford JM, Mc Ginn T, Davidson KW, et al. Presenting Characteristics, Comorbidities, and Outcomes Among 5700 Patients Hospitalized With COVID-19 in the New York City Area. JAMA 2020 May 26;323(20):20522059. doi: 10.1001/jama.2020.6775. Erratum in: doi: 10.1001/ jama.2020.7681. PMID: 32320003; PMCID: PMC7177629.

10. Ludvigsson JF. Systematic review of COVID-19 in children shows milder cases and a better prognosis than adults. Acta Paediatr. 2020 Jun;109(6):1088-1095. doi: 10.1111/apa.15270. Epub 2020 Apr 14. PMID: 32202343; PMCID: PMC7228328.

11. Sun D, Li H, Lu X, Xiao X, Xiao H, Ren J, et al. Clinical features of severe pediatric patients with coronavirus disease 2019 in Wuhan: a single center's observational study. World J Pediatr 2020 Jun;16(3):251-259. doi: 10.1007/s12519-020-00354-4. Epub 2020 Mar 19. PMID: 32193831; PMCID: PMC7091225.

12. Zhang JJ, Dong $X$, Cao YY, Yuan YD, Yang YB, Yan YQ, et al. Clinical characteristics of 140 patients infected with SARS-CoV- 2 in Wuhan, China. Allergy 2020 Jul;75(7):1730-1741. doi: 10.1111/all.14238. Epub 2020 Feb 27. PMID: 32077115.

13. Dong $X$, Cao Y, Lu X, Zhang J, Du H, Yan Y, et al. Eleven faces of coronavirus disease 19. Allergy 2020 Jul;75(7):1699-1709. doi: 10.1111/all.14289. Epub 2020 Apr 6. PMID: 32196678; PMCID: PMC7228397.

14. Guan W-J, Ni Z-Y, Hu Y, Liang W-H, Ou C-Q, He J-X, et al. China Medical Treatment Expert Group for Covid-19. Clinical Characteristics of Coronavirus Disease 2019 in China. N Engl J Med 2020 Apr 30;382(18):1708-1720. doi: 10.1056/NEJMoa2002032. Epub 2020 Feb 28. PMID: 32109013; PMCID: PMC7092819.

15. AAAAI: Asthma and COVID-19 Update. Erişim: https:// contentsharing.net/actions/email_web_version.cfm?recipient_ $i d=3712797199$ \& message_id=18453579\&user_id=AAAAI\&group_ id=0\&jobid=47601295. Son erişim tarihi: Eylül 2020.

16. CDC: Coronavirus Disease 2019 (COVID-19): People Who Are At High Risk. Erişim: https://www.cdc.gov/coronavirus/2019-ncov/ need-extra-precautions/asthma.html. Son erişim tarihi: Eylül 2020.

17. Abrams EM, Szefler SJ. Managing Asthma during Coronavirus Disease-2019: An Example for Other Chronic Conditions in Children and Adolescents. J Pediatr 2020 Jul;222:221-226. doi: 10.1016/j. jpeds.2020.04.049. Epub 2020 Apr 21. PMID: 32330469; PMCID: PMC7172836.
18. Shaker MS, Oppenheimer J, Grayson M, Stukus D, Hartog N, Hsieh EWY, et al. COVID-19: Pandemic Contingency Planning for the Allergy and Immunology Clinic. J Allergy Clin Immunol Pract 2020 May;8(5):1477-1488.e5. doi: 10.1016/j.jaip.2020.03.012. Epub 2020 Mar 26. PMID: 32224232; PMCID: PMC7195089.

19. Russell CD, Millar JE, Baillie JK. Clinical evidence does not support corticosteroid treatment for 2019-nCoV lung injury. Lancet 2020 Feb 15;395(10223):473-475. doi: 10.1016/S0140-6736(20)303172. Epub 2020 Feb 7. PMID: 32043983; PMCID: PMC7134694.

20. Sahng L, Zhao L, Hu Y, Du R, Cao B. On the use of corticosteroids for 2019-nCoV pneumonia. Lancet 2020 Feb 29;395(10225):683-684. doi: 10.1016/S0140-6736(20)30361-5. Epub 2020 Feb 12. PMID: 32122468; PMCID: PMC7159292.

21. Global Initiative for Asthma (GINA) 2020. Interim guidance on asthma management during the COVID-19 pandemic. Erişim: https://ginasthma.org/gina-reports/. Son erişim tarihi: 29.04.2020.

22. Lazzeri M, Lanza A, Bellini R, Bellafiore A, Cecchetto S, Colombo A, et al. Respiratory physiotherapy in patients with COVID-19 infection in acute settings: a Position Paper of the Italian Association of Respiratory Physiotherapists (ARIR). Monaldi Arch Chest Dis 2020 Mar 26;90(1). doi: 10.4081/monaldi.2020.1285. PMID: 32236089.

23. Simonds AK, Hanak A, Chatwin M, Morrell M, Hall A, Parker KH, et al. Evaluation of droplet dispersion during non-invasive ventilation, oxygen therapy, nebuliser treatment and chest physiotherapy in clinical practice: implications for management of pandemic influenza and other airborne infections. Health Technol Assess 2010 Oct;14(46):131-172. doi: 10.3310/hta14460-02. PMID: 20923611.

24. Zhonghua Jie He He Hu Xi Za Zhi. Respiratory Care Committee of Chinese Thoracic Society. Expert consensus on preventing nosocomial transmission during respiratory care for critically ill patients infected by 2019 novel coronavirus pneumonia. 2020 Apr 12;43(4):288-296. Chinese. doi: 10.3760/cma.j.cn11214 7-20200304-00239. PMID: 32294813.

25. Amitrav I. Newhause MT. Transmission of coronavirus by nebulizer: a serious, underappreciated risk. CMAJ 2020 Mar 30;192(13):E346. doi: 10.1503/cmaj.75066. PMID: 32392488; PMCID: PMC7124163.

26. Judson SD, Munster VJ. Nosocomial transmission of emerging viruses via aerosol-generating medical procedures. Viruses 2019 Oct 12;11(10):940. doi: 10.3390/v11100940. PMID: 31614743; PMCID: PMC6832307.

27. Türkiye Acil Tıp Derneği COViD 19 Havayolu Yönetimi Önerileri https://tatd.org.tr/uploads/files/COVID19\%2OHavayolu\%20 Yo\%CC\%88netimi\%200\%CC\%88nerileri.pdf

28. Bough HA, Kalaycı O, Sediva A, Untersmayr E, Munblit D, Del Rio $\mathrm{PR}$, et al. Managing childhood allergies and immunodeficiencies during respiratory virus epidemics - the 2020 COVID-19 pandemic A statement from the EAACI-Section on pediatrics. Pediatr Allergy Immunol 2020 Apr 22:10.1111/pai.13262. doi: 10.1111/pai.13262. Epub ahead of print. PMID: 32319129; PMCID: PMC7264548.

29. Editorial Lancet. COVID-19: Protecting Health-Care Workers. Lancet 2020,doi: 10.1016/s10140-6736(20)30644-9.

30. Webber CM, Calabria CW. Assessing the safety of subcutaneous immunotherapy dose adjustments. Ann Allergy Asthma Immunol. 2010;105:369-375.

31. Klimek L, Jutel M, Akdis C, Bosquet J, Akdis M, Bachert C, et al. Handling of allergen immunotherapy in the COVID-19 pandemic; an ARIA-EAACI statement. Doi:10.1111/ALL.14336. 